\section{SOME OVERLOOKED INVESTIGATIONS ON WHEAT}

Editor of the Journal of Industrial and Engineering Chemistry:

The Chemical Section of the Colorado Experiment Station has been engaged for several years in a study of Colorado wheat, to find out, if possible: (I) whether Colorado wheat has any distinctive quality which may be considered characteristic of it; (2) to determine the factor or factors in our conditions which are accountable for the same.

The result of our first two years' work was the publication of Bulletin 205 of this Station, entitled "Yellow-berry in Wheat; Its Cause and Prevention." Further reports on this work are contained in Bulletin 208 already issued, and 217 which will appear soon.

I endeavored to give credit in these publications to everyone to whom I am in any way indebted. I hold this to be the imperative duty of every author, even if his production should be of insignificant importance. Since the manuscript of Bulletin 2I7 was turned over to the Director of the Station, I have found that H. Ritthausen and Dr. R. Potts carried out a series of experiments in 1872 , an account of which may be found in Die landwirtschaftlichen Versuchs-Station, Band XVI, $1873, \mathrm{pp}$. 384-399, which, in the main, is parallel to mine to such, an extent, and the conclusions are so similar, that it might be thought that I had copied their plan of experimentation and adopted their conclusions. This applies to the bulletin on Yellow-berry to such an extent that some of my conclusions look like paraphrases of theirs. It does not apply to Bulletins 208 and 217 to the same extent. Still, it applies in some measure, and a portion of the work still to be reported will again be parallel.

Ritthausen and Dr. Potts used spring or summer wheat. They used nitrates and phosphorus on some of their plots alone and in excessive quantities. I, also, did these things, and for the same reasoris, but I used potash on some other plots and they did not.

They hold that climatic conditions as a cause for the quality of wheat is so general, indefinite and unsatisfactory that one must seek some more evident one-a view that I have repeatedly expressed, and which $\mathrm{I}$, in a general way, maintain in Bulletin 205, in which I show that it is insufficient as an explanation.

They state that their check plots produced light-colored, half-mealy or transitional kernels. The plots to which phosphoric acid or superphosphates were applied, produced the same kind of seed.

I record that my check plots produced grain affected with yellow-berry, mealy or half-mealy kernels, and that this condition was not affected by the application of phosphorus as superphosphate.

They record the effects of nitrate to be the production of small, well-formed kernels which were hard, flinty and dark-colored.

My statement is that the application of nitrate depresses or entirely prevents yellow-berry and produces small, flinty, and of ten shrunken berries.

They observed that nitrates used in conjunction with other fertilizers produced effects similar to those produced by nitrates alone. I have made the same observation.

I used potash on three series of plots and they did not. I observed that potash greatly increased the amount of yellowberry. They did not.

The examination of the kernels and flour also will run in their larger features parallel, which, of course, is to be expected. The two studies are not identical, but the general features are so similar that one might readily be considered a copy of the other, which is not the case.

My work was planned and three seasons' work done on my general project before I learned of the existence of this article, giving the record of this work done by these authors at Poppelsdorf... I. shall in no wise change the plan of my work, as I hoped from the beginning to carry my investigation far beyond its present stage. The work so far done seemed necessary, before it would be justifiable for me, or anyone else, to assign any cause or causes for the characteristics of our wheat. Indeed, it is not even yet certain that one can properly speak of Colorado wheats as having any predominant and fixed characteristic.

It is a matter of surprise to me that this work of Ritthausen's has received apparently no attention. I found an abstract of the article in the Journal of the Chemical Society, London. This abstract did not give a very adequate idea of the facts presented in the article. I have also found it mentioned in the literature given by Schindler, in his "Der Getreidebau" at the end of the section "Der Weizen."

$$
\begin{aligned}
& \text { Colorada EXPERIMENT Station } \\
& \text { Fort Collins, Colorado, January 21, } 1916
\end{aligned}
$$

W. P. HEADDEN

\section{TEMPERATURE CONTROL IN WOOD DISTILLATION}

Editor of the Journal of Industrial and Engineering Chemistry:

The note by Mr. R. B. Goetschius in This Journal 8 (1916), I96, on "Temperature Control in Wood Distillation Plants" has been read with much interest. Since much of the agitation on this subject referred to by him has been largely the result of experiments made by the United States Forest Products Laboratory the discussion is timely and of especial interest, as it affords an opportunity to clear up several points which are apparently misunderstood.

It is probably correct that the present design of wood distillation plants is not adapted to the greatest possible increases in products resulting from scientific temperature control but experiments in the laboratory, and also in commercial plants, subject to all the variables of factory operation have shown much greater possibilities along this line than is generally supposed by plant operators. The results of preliminary experiments which form the basis for this statement were given in ThIS JOURNAL, 7 (I9I5), 663.

Fortunately, it is not possible to control the distillation irrespective of any variation in size of pieces in a commercial size retort, so that all the water is distilled out of the charge before destructive decomposition takes place. Any control embodying such a conception would certainly result in a very.great absence of control during the latter stages of the distillation as the decomposition of a large volume of very dry wood is likely to be extremely violent.

Experiments by the Forest Products Laboratory have shown that apparently certain well defined relations exist between the rate of rise of the temperature in the retort, the flow of distillate, and the yield of products. The interaction between the various products in the retort in the presence of the hot charcoal undoubtedly plays an important part in the yields. Temperature control in the distillation of wood, as interpreted by these experiments, is then to make the greatest possible proportion of the distillations follow the proper combination of these factors which will give the best yields. A technical operation involving the rate of rise of the temperature as an important factor is obviously best conducted by employing pyrometers.

In a continuation of these studies in longer tests in commercial plants, results of which have not yet been published, it was found, strangely enough, that about equal mixtures of large pieces of split wood and smaller pieces of sawed wood more readily gave the desired rate of rise of temperature than either of the two kinds alone. Therefore, instead of requiring evenly sized wood in order to secure good results with pyrometers, possibly by proper control the variability of the size of wood may even prove an advantage.

Aside from this more scientific basis for the application of control there are other reasons which it would seem were alone sufficient for employing pyrometers in wood distillation plants. The great variability of raw material in size, moisture content, 